\title{
A Metacognitive Approach to Teacher Development: Supporting National Professional Diploma in Education (Npde) Students
}

Dr JD Adams

\author{
MS Mabusela
}

\author{
University of Zululand \\ Email: mabuselam@unizulu.ac.za
}

Doi:10.5901/mjss.2014.v5n15p289

\begin{abstract}
The paper presents how a metacognitive approach was implemented in an NPDE course to encourage reflective learning and to share insights on assessment and evaluation, particularly in a reflective environment. Qualitative descriptive research was deemed appropriate for this study. Data was collected by means of "reflection note books", group reflections, and evaluation forms, from a purposive sample of NPDE students. There was a specific activity which guided the type of relevant data for the purpose of the study. Quantitative and qualitative data analysis was employed. The study informs us that NPDE students seem to be struggling to monitor their own understanding and to be aware of their thinking. In addition, very few of them can construct new information on their own. Respondents found reflection uncomfortable where it requires specifying their weaknesses and comfortable where it requires strengths. Respondents found it is easier to practice reflection in an environment where there is support from the lecturer and classmates. Finally, respondents have mixed feelings about being exposed to the reflective approach. The findings are pointers that to the notion that respondents need to be supported in order to develop their capacity of reflect and to "think" about their "thinking" before they complete their professional studies.
\end{abstract}

Keywords: reflection; teacher development; teacher support

\section{Introduction}

The training, supporting and the developing professionals is the business of Higher Education institutions. There has been a growth in student support at almost all universities in South Africa, specifically for first year students who hail from the General education Band. The rationale for the provision of this support is that students are bringing with them numerous problems which may impinge on their studies. The commonly cited problems were that these students are under-prepared for the courses for which they register; they were also under-prepared in basic skills such as writing, reading and communication. The added problem is the fact that they received instruction in English which is the second and even the third language (Holtman \& McKenzie 1994). Other problems include the that fact these students are product of a high pupil- teacher ratio, inadequately trained teachers, lower qualifications, [ no qualifications] among Black teachers ( Hartman1989; Holtman and McKenzie 1994) and the socio-economic and political dispensation ( Adams 2006). Research reveals that first year college or university freshmen are on average unaware of their metacognitive strengths and strategies (Matanzo and Harris 1999) because the high school environment usually relies on approaches that foster surface learning. Worst of all, as pointed by Leamnson (1999), is that metacognitive instruction is generally not provided in tertiary settings despite research. Leamnson reveals that lack of the provision of Metacognitive instruction will result in freshmen depending on the use of the basic skills taught at middle school and high school level.

The situation that has been portrayed above is common among first year students but is not confined to them only. Experience and exposure of the researchers through lecturing to students at different levels has shown that all categories of students despite their age, gender, teaching exposure or teaching experience, whether as part-time students or fulltime may be affected by problems which may impact on their ability to maximise of their study opportunities. For NPDE students, these difficulties are more pronounced. A majority of these students are teachers who are inadequately trained, have low qualifications, or no qualifications at all. As is the case with all so-called under-prepared students, these students are not immune to failing to master basic academic skills such as formal argumentation, ability to understand lecture and text materials. The compounding factor for the majority NPDE students is that they use vernacular as a medium of teaching in their schools. The worrying factor is that the medium of instruction at institutions of higher education is English. That, on its own is anxiety provoking to students and worrisome to lecturers. 
Of significance to note also is that sometimes teacher training programmes are fraught with shortcomings to the extent that effective learning becomes impossible. For example, as early as 1996, The National Audit Synthesis Report released by Hofmeyer and Hall (1996) highlighted problems associated with teacher training programmes. The problems were spelt out as: (1) instructional approaches that are teacher centred rather than student centred; (2) a lack of integration of theory and practice; and (3) failure to inculcate the habit of reflection in prospective teachers. This report better captures the idea that as lecturers we need to review our practice of training to enable future teachers not only to be effective teachers but also to be effective learners. One strategy of achieving this goal includes revisiting our instructional approaches.

Experience has shown that Instructional approaches that are lecturer - centred have occupied a centre stage in lecturing at higher education domain. The most popular among these approaches is the lecture method. One does not need to be highly gifted to understand why most lectures prefer it. Experience in using this method has shown that it is good for big classes; the lecturer becomes the authority of knowledge; and students become disciplined because they want to be provided with notes or take notes. The salient feature of the lecture method is that it reduces students to "passive recipients" of the lecturer's knowledge. With an excessive use of the lecture method, students are deprived of an opportunity do self-monitoring and self-evaluation of their learning, including active interaction with the learning material. The researchers are arguing in favour of Metacognitive instruction.

Metacognition refers an appreciation of what one already knows, together with a correct apprehension of the learning task and what knowledge and skills it requires, combined with the agility to make correct inferences about how to apply one's strategic knowledge to a particular situation, and to do efficiently and reliably (Taylor (1999). Metacognition" is often simply defined as "thinking about". According to Schraw (1998), metacognition consists of both Metacognitive knowledge and Metacognitive experiences or regulation. Metacognitive knowledge refers to acquired knowledge about cognitive processes, knowledge that can be used to control cognitive processes. Awareness of one's own thinking and increasing knowledge ability about cognition and the learning process enable students to learn more effectively (Pintrich 2002). Research has also emphasized that students should be afforded with opportunities to self-assess as a basis for developing a repertoire of regulatory learning strategies (Zimmerman 2002).

One of the most promising types of intervention for facilitating the development of metacognitive skills involves reflection as technique to make thinking processes more visible (McCormick 2006). The notion of reflection in teaching is really about metacognition in teaching (Harrison, short and Roberts, 2003; Sawyer 2006). Reflection allows students to evaluate their personal strengths and weaknesses (Harrison et al. 2003). Reflection is particularly relevant where students have to react strategically and make choices about their learning (Evans, Kirby \& Fabrigar, 2003). Reflection can supply information about outcomes and effectiveness of selected strategies thus making it possible for a learner to gain strategic knowledge for specific learning activities (Ertmer \& Newby 1996). Reflection leads to growth of the individual morally, personally, psychologically, emotionally, as well as cognitively (Branch \& Paranjipe 2002). It can positively affect professional growth and development by leading to greater self- awareness, to the development of new knowledge about professional practice, and to broader understanding of problems that confront practitioners (Osterman 1990). Studies encourage the use of reflection, thus the application of metacognition strategies.

The minimal or lack of use of the Metacognitive approach in higher education is a serious indictment, given the problems that these students (NPDE) bring at the university. These students are also more likely to use or depend on the approaches they used as teachers on their learners as they might have problems of disengaging from being "transmitters of knowledge" to being "seekers of knowledge." Hoffman (2000) argues that learning may not occur fully unless a student learns to monitor his or her own learning. Researchers as instructors have a responsibility of assisting students to identify their Metacognitive skills. Singler and Tallen-Runnels (2006) opine that identifying the basic mechanisms of the individual's Metacognitive behaviours may lead to the creation of methods to improve learning for that individual. If individuals have control over these processes, they can do something about them as decisions lead to actual performance (Runco, 2004).

Metacognition is grounded in constructivists' theory (Narode 1989). Vygotsky (1978), one of the proponents of this theory argues that social interaction plays a fundamental role in the process of cognitive development. This includes involvement of others with more understanding than the learner (the more knowledge other-MKO); the zone of proximal development (ZPD) and the distance between the student's ability to perform a task under adult guidance and /or peer collaboration to solve problems independently. The merit of this theory is that meaning construction and knowledge is gained through social interaction and through knowledgeable individuals than themselves. According to the constructivists theory learning cannot be assumed to have occurred simply because information was presented and individuals listened and said they understood what was intended (Kamii 1982). The researchers deemed it appropriate to expose NPDE students to a reflective activity and a reflective culture so as they could be afforded an opportunity to 
appraise their own cognitive processes for the purpose of achieving a goal - that is "stepping out of oneself "and critically appraising one's performance for the sake of "self-comprehension".

Various studies have been conducted to show the applicability and efficiency of the Metacognitive approach at higher education. Phelps, Ellis and Hase (2001) investigated the role of Metacognitive and reflective processes in developing capable computer users. The researchers concluded that reflection and metacognition is central to the development of 'expert learners' and can potentially be seen to provide a sound framework for the development of capable computer users. Another study (Graham and Phelps, 2003) explored the rationale of the use of the Metacognitive and reflective processes in developing identity and enhancing practice and they found that some students embraced the notion of reflective practice as more than just a thoughtful process. They discovered also that reflective thinking is not something that occurs easily and that some students found reflection an uncomfortable and hard process. Jing (2006) researched on teaching and reflection on Chinese students learning as a second language. The findings of the study revealed that students could not see the value of using Metacognitive approach and that they were not interested in using the skills and strategies provided by the approach. Research studies (Jing 2006; Phelps et al. 2003) have shed light into the fact that not all students will take kindly to exposure to Metacognitive strategies. Literature has provided suggestions on how to overcome negativity which might accompany resistance regarding using Metacognitive strategies with students. Deed $(2009,485)$ asserts that "moving students from passive to active learning requires considerable effort on behalf of the lecturer. Metacognition is a complex and abstract idea for students to negotiate. Instructional tasks need to be carefully structured, including provision for Metacognitive discussion."

\section{Problem Statement}

NPDE students as a cohort which is inadequately trained, have low qualifications, or no training at all - fail to master basic skills such as formal argumentative skills, ability to understand lecture and text material , let alone" awareness of their cognitive machinery and how the machinery works" ( Meichenbaum, Burland Cruson \& Cameron, 1985, p.5). The problem of these students is compounded by the fact that they are so accustomed to using instructional approaches that are rather teacher centred than learner centred in their own teaching. During their studies at tertiary institutions, they are mostly exposed to the same methods by lecturers. Continual exposure of students to these methods coupled with the problems they bring to university, will result to under-developed professionals. The researchers are hoping to produce grounded teachers. The researchers also believe that students tend to learn more effectively when good support systems and teaching strategies are considered in making them effective learners. Considering that Metacognitive strategy help students plan, monitor their own understanding and to be aware of their thinking, the researchers felt that there is need to expose NPDE students to the approach. The study sought not only to develop students 'to think about their thinking', but also document their experience of the exposure to this methodology since literature on supporting NPDE students through the Metacognitive approach remains scarce. The research problem of this study is articulated through the following research questions:

1. How do students respond to reflective learning?

2. How applicable are the assigned readings to their profession and / or personal lives?

3. What did the students discover about themselves during self-evaluation?

4. How students felt about sharing their reflections as individuals and / or with others?

5. What are the strengths and weaknesses of reflective learning?

6. What are the opinions of students towards being exposed to reflective learning?

\section{The Significance and Contribution of the Study}

The significance and contribution of this study will be enormous. Amongst other things it will reveal empirical evidence of the applicability of the Metacognitive approach of teaching NPDE students. Such information would be useful in supporting the fact that different methods of teaching students should be explored. Findings would hopefully influence the way in which students learn, including the manner in which they are taught.

\section{Research Design and Methods}

The study is located in the non - experimental design. A qualitative research was deemed to be an appropriate mode of inquiry for this study which sought to provide information about experiences of students regarding the use of the Metacognitive approach. Participants involved a purposive sample of 40 NPDE students registered for the Teaching and 
Learning strategies module in the Faculty of Education. A majority of these students are teachers who are inadequately trained, have low qualifications, or no qualifications at all. A large number of them come from far deep rural areas of Kwazulu-Natal in South Africa. Research (Sajjad, 2009) indicates that students are the qualified sources to report on extent to which a learning experience was productive, informative, satisfying and worthwhile. A "reflection note book" was used to collect data. It comprised of six open ended questions they had to respond to. The rationale for including open ended questions was to provide students with an opportunity to express themselves freely and to be able to use analytic and thinking skills, creative thinking, and problem solving skills to and to enable them to reflect on their learning experiences. The students first engaged in the activity and thereafter completed an evaluation questionnaire. Before the subjects could complete the questionnaire the researchers assured them of confidentiality and anonymity. The subjects were also made aware that information derived from their analysed responses would be used to improve future sessions and would be disseminated to the professional community. Descriptive statistics was used to analyse the close -ended statements of the evaluation questionnaire. Qualitative data was thematically analysed using the following steps: (1) All the descriptive responses were read several times; (2) responses to each question were written on a separate sheet;(3) the responses to each question were examined separately to ascertain similarities and differences; (4) names were given to categories of descriptive responses; (5) the themes identified were explicated.

\section{Research Findings}

\subsection{Qualitative findings}

Information from students' "reflection notebooks was analysed." The reflection notebooks were given back to the students and were the basis for discussion about issues they would like to have discussed further in class. Students were then given an opportunity to share their reflections as groups. They had to elect a scribe to document their ideas, including someone who would present crucial issues for their group.

To answer research question (1): How do students respond to reflective learning? Students' summaries - which dealt with active learning were analysed and the findings reveal that the majority of students did not summarise the main points of the reading as was instructed. Only three students summarized and engaged critically with the material that was to be summarized. Most students reproduced the content of the reading; two students wrote notes about everything that was learnt in the Teaching and Learning strategies module. Other students wrote summaries of excerpts they chose for themselves,

To address research question (2): How applicable are the assigned reading to their profession and/ or personal lives? The researchers' analysed information related to the relevance of the readings to the students' teaching and learning. Most students did not respond to this section of reflection. One student who responded accordingly asserts:

'The reading was relevant because I can see different views from different scholars. Bruner and Ausubel have their own view ....and I felt that they are both applicable in my classroom. I say that because I let learners explore through play...'

To answer question (3): What did students discover about themselves during self-evaluation? Students were involved in self-discovery and self-evaluation by encouraging them to identify potential impediments to what they have learnt, including identifying their strengths and weaknesses. On analysing students' responses, it became evident that most of the students responses did not relate to impediments they discovered about themselves during self-evaluation, but rather were responses related to impediments affecting their learners for example: lack of resources, late coming, and absenteeism, poverty. Inability to express themselves in English (both written expression and verbal expression) was identified as major set-backs. The following confessional remarks are worth quoting:

\footnotetext{
'It is difficult to write a summary of something in English because I know that I am not good at it.'

And

"I teach Grade $R$ and I teach these children in isizulu and it is difficult for me to write summary in English. Most of the time I rewrite what I am told to summarise.'
}

The majority of participants were not forthcoming when it came to expressing their weaknesses. One of them expressed her weaknesses but these did not relate to the reflection of learning. This is illustrated by the following comment:

'My weakness is shouting, nagging learners... To improve my weaknesses I will try not to be mad at them.' 
In contrast to weaknesses what then were strengths that students identified in them? It is notable that most respondents expressed the strengths they discovered in descriptive words as will be noted: loving, honest, encouraging, confident; good time management; good memory, self -reliance, discipline, interpersonal skills.

'To answer research question (4): How students felt about sharing their reflections as individuals and /or with other? Students were randomly selected to share their individual reflections. Support was offered to those who seemed to be struggling and those felt they need it. During the reflection-sharing time students learnt from each other contributions and they were exposed to different interpretations of the readings. This how some students felt:

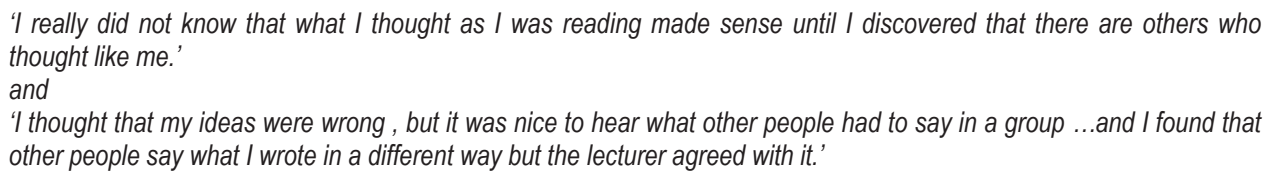

To address research question (5): What are the strengths and weakness of reflective learning? Students had to furnish strengths and weaknesses of reflection in underpinning the Metacognitive approach to developing ability to selfmonitor and to evaluate one's cognitive activities during task performance. The strengths of reflective learning are illustrated by a number of students who made a connection between reflection and group-learning techniques such as cooperative learning and peer tutoring; including improving communication skills. This situation can be exemplified by the following assertions:

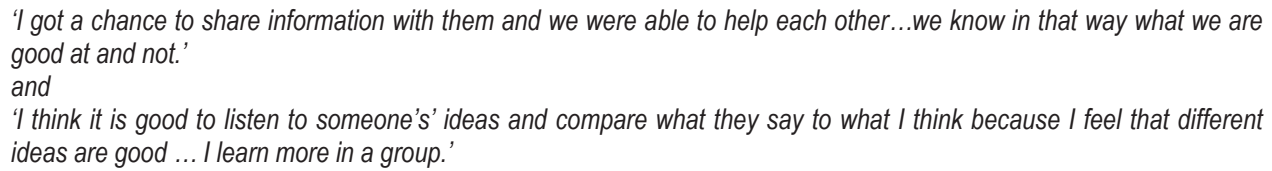

The major weakness of the approach related to the fact that most students felt that it was difficult to work as an individual at home without a lecturer explaining. They also saw the method as demanding. Generally they viewed the reflective practice as weak in that it does not accommodate those who cannot express themselves in writing. This is illustrated by the following comment:

I don't like to make work that makes me write a summary because I'm not good in writing good English. I wrote something because I have to write.'

\subsection{Quantitative findings}

To address research question (6): What are the opinions of students towards being exposed to reflective learning? After completing an evaluation regarding how they experienced being exposed to reflective learning, the quantitative findings revealed that $52 \%$ of the group reported an unpleasant experience while the remainder (48\%) reported a pleasant experience. There is almost a balance of opinion between those expressed a positive opinion and those who expressed a negative opinion.

\section{Discussion}

A number of significant findings have emerged from this study. First, after many years of teaching experience many NPDE students find it hard to engage with written material without the interpretation and the guidance of a lecturer. These findings indicate that the majority of NPDE seem to lack requisite skills necessary for interacting with material individually, including ability to follow instructions. The compounding factor might be that the material is English. The results also show that reflective learning to the respondents is something far-fetched and difficult to practice. These findings are consistent with those of Graham and Phelps (2003) who discovered that some students found reflection an uncomfortable and hard process; and those of Jing (2006) who found that students were not interested in being equipped with Metacognitive skills like reflection, but wanted the facilitator to provide them to with information to pass examinations.

Second, integration of material learnt in class and material leant in other contexts including the students' own personal and professional experience is difficult for a majority NPDE students. The excerpts revealed that some students did use the reflective approach to devise ways of applying what they learnt to their professional practice, albeit very few of 
them. Of concern is the majority of students did not use this opportunity to self-monitor and examine their thinking. This is indeed agitating to the researchers as it means most respondents rely on surface leaning and thus find it difficult to think about thinking as they learn. The findings also indicate that respondents have unique cognitive needs that have to be taken into consideration when adopting new teaching and new intervention approaches to learning. This observation confirms Stahl's (1992) theory that new ideas, information or concepts, cannot be simply transferred from one person to another as often assumed. In other words ability to reflect and the pace to master reflection differ from person to person.

Third, going through self-discovery by NPDE students appears to be a difficult process as revealed by the fact that they avoided exposing impediment and their weaknesses on request, but they were forthcoming in exposing their strengths; yet research ( Harrison, et al. 2003) suggests that evaluating their personal strengths and weaknesses and runs parallel with metacognition. Respondents furnished information about impediments affecting their learners rather providing information about impediments pertaining to themselves. This in essence means that they regard themselves as immune from having learning impediments as evident in their responses which were reduced to a list of impediments affecting teaching and learning in their schools. The majority of respondents revealed a tendency to be more concerned about what happens when they teach than what they learn . It appears that it is still difficult for them to disengage from the position of teacher to that of a student. They also seemed to be worried about whether their teaching skills are up to the accepted standard or not, looking at many concerns relating to the lesson plan and teaching methodology.

The respondents also appeared to be anxious about problems affecting their learners; some of which are caused by intrinsic factors while others are caused by extrinsic factors. These findings indicate that equipping students who are already teaching with skills of solving their own problems is not easy, as they appear to be more concerned about problems of learners than their own learning problems. They regard themselves as immune from impediments - whether as students or as educators. Secondly these students rarely see themselves as learners as they are used to occupying the position of the disseminator of knowledge. These findings have opened some of the complexities involved in their responsibilities as educators.

Respondents found reflection comfortable where it requires specifying their strengths. Generally the respondents viewed themselves as adequate with regards to working with classmates and learners. They were forthcoming in exposing their strengths without fear as evidenced by a long list of positive attributes documented on their reflection notebooks and also how they expressed these in class with confidence.

Fourth, for students it is easier to practice reflection in an environment where there is support from the lecturer and classmates. The discomfort that existed when some students had to do the critical reading was reduced. What was also noted was that for the presentations the majority of students came to class fully prepared. What seemed to be lacking was ability to adopt a critical approach to what was read. As students did their presentations they were further guided to think analytically about their readings and to paraphrase the assigned readings to produce summaries.

Fifth, the majority of students perceive strengths of Metacognitive, reflection in particular as promoting interaction. This meant that the strategy of allowing group reflection has created a platform for cooperative learning and peer support. This was observed as students were reflecting in small groups. They learnt to work with one another and to communicate ideas. They felt less threatened having their ideas being challenged by their peers than they would, being challenged by the lecturer. This finding accords with the constructivist theory which argues that social interaction plays a fundamental role in the process of cognitive development (Vygotsky, 1978). The respondents also perceived the strength of reflective learning as equipping them with skills of reflective teaching because they saw it as method that enabled them to monitor and evaluate their own practice as teachers. The behaviour expressed by respondents indicates that they seem to be preoccupied with their teaching effectiveness rather than their learning ability. It appears that the respondents have used the reflection activity to expose what they have acquired in form of expertise in their tenure as teachers - whether unqualified or under-qualified. The participants viewed the approach as too demanding. This might be attributed by the fact that they had to read, critically analyse, interpret and relate information to other similar situation on their own before peer involvement. Another reason might be that reflection requires a level of concentration and a command in the language of instruction - English. For a majority of respondents expressing themselves with confidence in English appeared to be a night mare as they were second language speakers and to crown it all have used vernacular during their teaching years to date.

Finally, respondents have mixed feelings (positive and negative) about the reflective approach. These results are not surprising as self-assessment and monitoring one's thinking and actions leads to greater self-awareness of what works well and what does not well learning so some students will find it to be a comfortable experience while others will find it an uncomfortable. These findings support those of Graham and Phelps (2003) who found that reflective thinking is something that occurs easily and that some students found reflection an uncomfortable and hard process. An explanation for the discomfort might be attributed to the fact that when students have to take responsibility for their learning they do 
not take kind to it due to the fact that they are accustomed to traditional methods like the lecture method.

Another reason might be that self-inquiry is not easy as it involves standing back in order to in think deeply about the given and not reproducing the given. The approach might also appear to be too demanding as interrupts their home and work schedule as the reflection activities have to be done as home work. Finally self-inquiry interferes with their selfimage and self-esteem as they view themselves as teachers - not as the unqualified or the under qualified.

\section{Conclusion}

The study outlined here, has explore how a Metacognitive approach was used on NPDE students as a vehicle to engage students in a reflective practice and as an alternative method to develop student learning looking at highlighted barriers that affect the NPDE student's learning. Implementing approaches that are needed to enable students to construct new information on their own and be primarily responsible for the mastery of given tasks appears to be a challenge in higher education at present, especially when dealing with NPDE students. Current findings inform us that NPDE students seem to be struggling to monitor their own understanding and to be aware of their thinking. In addition, very few of them can construct new information on their own. This means that the majority will not be aware of areas that need improvement and growth in both personal and professional contexts. The implication of this is that they would not be able to impart skills like problem solving, creative, analytic and thinking skills to their learners. Furthermore, some students experience difficulties when engaging in reflective activities alone while others do not. The findings are a pointer that to the notion that not all learning approaches will suit all students. This does suggest that other learning approaches should not be utilised. This simply indicates that when using teaching and learning strategies it is very crucial to be well-grounded, not in learning theories, but also in theories of adult learning, as well as individual differences.

Attention is also drawn to the fact when one uses the Metacognitive approach to encourage reflective learning, one must be mindful of the fact that attributes like anxiety and shyness from some students, including interdependence in learning may prove to be a barrier to some students. It must also be acknowledged that students have different learning styles; as a result the reflective intervention must be designed with these in mind. It is noteworthy that very few students were prepared to admit their learning weaknesses and to criticize themselves without negative reaction from their peers and their lecturers. The implications of these findings are that students will need to know that reflective learning is a strategy of assisting them to recognize a range of transferable skills learnt and those that still require to be developed. Students will need to be convinced that reflecting on learning is legitimised by their course and the profession as a whole, resulting to positive outcomes in teaching and learning as well as in personal development terms.

Lastly, it must be acknowledged that teaching students who are already in the field has its challenges. It must be noted that these students suffer psychological dissonance when they realise that they have to occupy the position of being students and be lectured to, yet they perceive themselves as authorities of knowledge in the teaching fraternity. This is one of the reasons they would focus on reflective teaching when they asked to reflect on their learning. This implies that instructors must be wary of this tendency and try to re-direct future reflective learning activities in order to lead students to meaningful insights of cognitive abilities.

The present investigation sought to raise issues for debate rather than seeking to furnish answers to complexities inherently involved in developing and supporting NPDE students through using a variety of teaching methodologies. The bottom line is that Future teachers need to be effective learners and also effective teachers of learning (De la Harpe and Rudolf, 1999). In other words, it is incumbent on students to develop their capacity as learners as well as teachers. It is also incumbent on instructors to provide support and professional development through using reflection and Metacognitive processes, (not at the exclusion of other methodologies) before students complete their studies.

\section{References}

Adams, J. D. (2006). Prevailing and preferred learning practices in student support. Unpublished doctoral theses. University of Zululand. South Africa.

Branch, (Jr) W. T and A. Paranjipe. (2002). Teaching methods for clinical settings. Academic Medicine. 77(12), 1185-1188.

Deed, C. (2009). Strategic Questions: A Means of building Metacognitive Language. International Journal of Teaching and Learning in Higher Education, 20 (3), 481- 487.

De la Harpe, B \& Rudolf, A. (1999). Helping future teachers to be effective learners: providing in-context learning support for first year Teacher Education students. Australian Journal of Teacher Education, 24(2), 35-41.

Ertmer, P. A \& Newby T.J. (1996). The expert learner: Strategic, self-regulated and reflective. Instructional Science, 24: 1-24.

Evans, C. J, Kirby J.R \& Fabrigar L.R. (2003). Approaches to learning, need for cognition, and strategic flexibility among university students. British Journal of Educational Psychology, 73, 507- 528. 
Graham, A P \&. Phelps, R. (2003). Being a Teacher: Developing teacher identity and enhancing practice through metacognitive and reflective learning processes. Australian Journal of Teacher Education, 27 (2).

Harrison, T, Short, C and Roberts, C. (2003). Reflecting on reflective learning: The case of geography earth and environmental sciences. Journal of Geography in Higher Education, 27, 133-152.

Hartman, N (1989). Syndicate-based peer learning: and alternative process. South African Journal of Higher Education, 3(1), 98-106.

Hoffmann, D J (2000). Metacognition and multiplicity: The arts as models and agents. Educational Psychology Review, 12, $339-517$.

Hofmeyer, J \& Hall G. (1996). The National Teacher Audit : Synthesis Report . Pretoria South Africa: National Department of Education.

Holtman, L \& . McKenzie ,B. (1994). Pre-instruction and post -instruction testing: assessing students' existing conceptual knowledge and predicting their potential academic performance. Paper presented at a SAAAD Conference. University of Natal, December 1994.

Jing, $H$ (2006). Learner resistance in mataconitive training? An exploration of mismatches between learner and teacher agendas. Language teaching research, 10, $95-117$.

Kamii, C (1982). Constructivist education: A direction for the twenty first century Report No. PS-01-3070). Chicago: University of Illinois. (ERIC Reproduction Service No . ED 221 297).

Leamnson, R (1999). Thinking about teaching and learning: Developing habits of learning with first year college and university students, Sterling, VA: Stylus.

Matanzo J. B and Harris D.L,. (1999). Encouraging metacognitive awareness in pre-service literary courses: Advancing the world of literacy. Florida Atlantic University.

McCormick, C. B. (2006). Metacognition and learning. In P. Alexander, \&P. H. Winne (Eds.) Handbook of Educational Psychology (2nd ed). Mahwah, New Jersey: Lawrence Erlbaum.

Meichenbaum, D, S. Burland ,L. Cruson L \& Cameron R. (1985). Metacognitive assessment . In S Yussen ( Ed), The growth of reflection in children ( pp1-30). Orlando , FL; Academic press.

Narode, .R. (1989). A constructivist program for college remedial mathematics at the University of Massachusetts, Amherst (Report No. SE-050-830) Amherst, MA: University of Massachusetts, Scientific Reasoning Institute. (ERIC Reproduction Service No. ED 309 988).

Osterman, K. F. (1990). Reflective Practice: A new agenda for education: Education and Urban Society, 22(2), 133-152.

Phelps, R, Ellis A \& Hase S. (2002). Overcoming computer anxiety through reflection on attribution. Conference of Australian Society for Computer in learning in tertiary Education,(ASCILITE): 8-11 December 2002 , Institute of technology, 2, 515-524.

Pintrich P. R., Wolters C.A. \& Baxter G.P. (2000). Assessing metacognition and self- regulated learning. In G Schraw \& J. Impara (Eds.), Issues in the Measurement of Metacognition (pp.43-97). University of Nebraska: Buros- Nebraska Series on Measurement and Testing.

Runco, M.A. (2004). Creativity as extracognitive phenomenon. In L. V. Shavinina and M. Ferreri (Eds.),Beyond Knowledge: Extracognitive Aspects of Developing High Ability . New Jersey: Lawrence Erlbaun.

Sajjad, S. (2009). Effective Teaching Methods at Higher Education Level. Proceedings from the WFATE International Conference held on 12-13 February 2009 at Chicago, Illinois.

Sawyer, R. K. (2006). Introduction: The new science of learning. In R K Sawyer(Ed), The Cambridge handbook of learning sciences ( $2^{\text {nd }}$ ed ). New York:. John Wiley and Sons.

Schraw, G. (1998). Promoting general metacognitive awareness. Instructional Science, 26 (1-2), 113-125.

Sigler, E. A \& Tallen-Runnels M.K. (2006). Examining the validity of scores from an instrument designed to measure metacognition of problem solving. The Journal of General Psychology. 133, 257-276.

Stahl, R. J. (1990). What students need to become successful learners: An information constructivist perspective on school learning, Part 1. Paper presented at the annual meeting of the National Association of Research in Science Teaching (NARST), Atlanta, GA.

Taylor, S. (1999). Better learning through better thinking: Developing students' metacognitive abilities. Journal of College Reading and Learning, 30(1),34 ff. Retrieved June2, 2011 form Expanded Academic Index ASAP.

Vygotsky, L. S. (1978). The development of higher mental processes. Cambridge: Harvard University Press.

Zimmerman, B. J. (2002). Becoming a self-regulated learner: An overview. Theory into Practice, 41(2), 64-70. 